\title{
A Milroy Disease Family Caused by FLT4 Gene Mutation of c.2774 T>A
}

Yu Sui

Key Laboratory of Reproductive Health and Medical Genetics, Liaoning Province Research Institute of Family Planning,China Medical University Yongping lu

Key Laboratory of Reproductive Health and Medical Genetics, Liaoning Province Research Institute of Family Planning,China Medical University Meina Lin

Key Laboratory of Reproductive Health and Medical Genetics, Liaoning Province Research Institute of Family Planning,China Medical University Xiang Ni

Key Laboratory of Reproductive Health and Medical Genetics, Liaoning Province Research Institute of Family Planning,China Medical University Xinren Chen

Key Laboratory of Reproductive Health and Medical Genetics, Liaoning Province Research Institute of Family Planning,China Medical University Huan Li

Key Laboratory of Reproductive Health and Medical Genetics, Liaoning Province Research Institute of Family Planning,China Medical University Miao Jiang ( $\square$ jiangmiao@Inszjk.com.cn)

Key Laboratory of Reproductive Health and Medical Genetics, Liaoning Province Research Institute of Family Planning,China Medical University

\section{Research Article}

Keywords: Milroy disease, FLT4 gene, heterogeneity

Posted Date: January 4th, 2021

DOl: https://doi.org/10.21203/rs.3.rs-129626/v1

License: (c) (1) This work is licensed under a Creative Commons Attribution 4.0 International License. Read Full License 


\begin{abstract}
Background: Milroy disease (MD) is a rare, autosomal dominant disorder. Mutations in the Fms-related tyrosine kinase 4 (FLT4) gene cause the symptoms of this disease. In this report, we investigated the mutations in a large Chinese family with MD.

Methods: We conducted Sanger sequencing of exons 17-26 of the FLT4 (NM_182925.4) gene. The primers were as follows: forward, 5' CTTCATCAGCGTCGAGTGG 3' and reverse, 5' ATTATGGGCGGGTTCCTT 3'. The amplification system is as follows: 2×Biotech Power PCR Mix, $10 \mu$ l; forward primer, $0.8 \mu \mathrm{l}(10 \mu \mathrm{M})$; reverse primer, $0.8 \mu \mathrm{l}(10 \mu \mathrm{M})$; DNA template, $1 \mu \mathrm{l}(50 \mathrm{ng} / \mu \mathrm{l})$; and ddH2O, $13.4 \mu \mathrm{l}$. The mutation was evaluated with MutationTaster, SIFT and PolyPhen.
\end{abstract}

Results: A heterozygous substitution was detected in all patients but not in any healthy controls (FLT4 gene: c.2774 T>A, p.V925E). The mutation was predicted to be pathogenic.

Conclusions: In this report, we described a large family with MD caused by a missense mutation of the FLT4 gene (c.2774 T>A, p.V925E).

\title{
1. Background
}

Primary hereditary lymphoedema type IA (LMPH1A, OMIM\#153100), also known as Milroy disease (MD), is a rare, autosomal dominant disorder [1]. Characteristic symptoms include painless and nonprogressive lymphedema with uni- or bilateral edema of the legs and feet [2-4] and prominent venous vessels [2], congenital hand edema [5], persistent bilateral pleural effusion with high protein levels [2-4] and scrotal swelling [2]. The Fms-related tyrosine kinase 4 (FLT4) gene (also known as vascular endothelial growth factor receptor 3, VEGFR3) encodes a receptor tyrosine kinase [6-9] and is important for lymphatic endothelial cell survival, proliferation and migration $[10,11]$. FLT4 gene mutations impair tyrosine kinase signaling and cause MD [12]. In this study, we explored a large Chinese family with MD and identified possible pathogenic mutations.

\section{Methods}

\subsection{Pedigree construction}

The propositus with suspected primary lymphedema was self-referred to our research team and was examined by lymphological specialists and medical geneticists (Miao Jiang). Then, we constructed a family history. All participants underwent a series of clinical examinations for primary lymphedema. The recruited patients satisfied at least one of the following criteria: lower extremity lymphoedema, pitting edema, hyperkeratosis and subcutaneous thickening. We also assessed the nail plate morphology of the patients. Secondary lymphedema was excluded after medical history inquiries: the patients were asked if they had filariasis, cancer, infection, radio-/chemotherapy and surgery. Genetic counseling was offered to the family members when the pathogenic mutation was identified. The local research ethics committee approved the study protocol.

\subsection{DNA extraction}

Blood samples were obtained from all family members. We recruited 100 healthy individuals from the same geographical areas as the patients to clarify whether the possible mutation was an innocuous polymorphism or pathogenic mutation. Genomic DNA was extracted from the blood samples using a DNA Isolation Kit for Mammalian Blood (Tiangen Biotech, China).

\subsection{PCR amplification and Sanger sequencing}

We sequenced exons 17-26 (tyrosine kinase coding domains) of the FLT4 gene in all family members (Sangon Biotech, Shanghai, China). The primers and conditions for the PCR amplification of the FLT4 gene (NM_182925.4) are provided in the supplementary materials (Table S1: PCR amplification system and conditions for the tyrosine kinase coding domains of the FLT4 gene). The primers for amplification of exon 20 were as follows: forward primer, $5^{\prime}$ CTTCATCAGCGTCGAGTGG 3' and reverse primer, $5^{\prime}$ ATTATGGGCGGGTTCCTT 3'. The PCR conditions for amplification of exon 20 of the FLT4 gene were as follows: denaturing at $95^{\circ} \mathrm{C}$ for $5 \mathrm{~min} ; 35$ cycles of denaturing at $95^{\circ} \mathrm{C}$ for $30 \mathrm{~s}$, annealing at $58{ }^{\circ} \mathrm{C}$ for $30 \mathrm{~s}$, and extension at $72{ }^{\circ} \mathrm{C}$ for $30 \mathrm{~s}$; and a final step for $7 \mathrm{~min}$ at $72^{\circ} \mathrm{C}$ The amplified fragment is $176 \mathrm{bp}$. The amplification system was as follows: $2 \times$ Biotech Power PCR Mix, $10 \mu l ;$ forward primer, $0.8 \mu \mathrm{l}(10 \mu \mathrm{M})$; reverse primer, $0.8 \mu \mathrm{l}(10 \mu \mathrm{M})$; DNA template, $1 \mu \mathrm{l}(50 \mathrm{ng} / \mu \mathrm{l})$; and ddH2O, $12.4 \mu \mathrm{l}$. The amplification reaction was $25 \mu \mathrm{l}$. The novel mutation was also ruled out as a polymorphism by digestion with the restriction enzyme $\mathrm{Hphl}$, and the amplification primers were as follows: 5' AACCTCCTCGGGGCGTGCACCAAGC 3' and 5' GCGCAGGGGCTGAAGGCGTCCCG 3'. The amplification system was as follows: $2 \times$ Biotech Power PCR Mix, $10 \mu$; forward primer, $0.8 \mu \mathrm{l}(10 \mu \mathrm{M})$; reverse primer, $0.8 \mu \mathrm{l}(10 \mu \mathrm{M})$; DNA template, $1 \mu \mathrm{l}(50 \mathrm{ng} / \mu \mathrm{l})$; and ddH2O, $12.4 \mu \mathrm{l}$. The PCR amplification conditions for the $F L T 4$ gene were denaturing at $98^{\circ} \mathrm{C}$ for $30 \mathrm{~s}$; 35 cycles of denaturing at $98^{\circ} \mathrm{C}$ for $30 \mathrm{~s}$, annealing at $58^{\circ} \mathrm{C}$ for $30 \mathrm{~s}$, and extension at $72{ }^{\circ} \mathrm{C}$ for $30 \mathrm{~s}$; and a final step for 7 min at $72{ }^{\circ} \mathrm{C}$. The $\mathrm{PCR}$ amplification fragment is $262 \mathrm{bp}$.

\subsection{Mutation analysis}

We searched human FLT4 protein homologs using BLAST on the NCBI website (http://www.ncbi.nlm.nih.gov). The identified proteins were aligned using ClustalW [13], and a phylogenetic tree was reconstructed with MEGA4 with the neighbor-joining method [14]. We evaluated the effect of the amino acid substitution on the protein function with MutationTaster (www.mutationtaster.com), SIFT $[15,16]$ and PolyPhen.

\section{5 informed consent of the research}

All participants enrolled into this research had given written consents to participate after being informed of the nature of the research. All family members enrolled in the study signed two informed consent forms: one for the genetic test and the other to make the clinical and genetic data available for research 
purposes. Signed informed consent was obtained from all members of the studied family for publication of personal and clinical information (images included) in this research.

\section{Results}

\subsection{Description of the MD pedigree}

The pedigree had 4 generations of Chinese patients, all living in Southeast China (Shenyang City, Liaoning Province), and the pedigree includes 7 patients (age ranging from 29 to 75 years old) and 8 healthy controls (Fig. 1: Pedigree of the family). Table 1 shows the clinical features of all 7 patients (Table 1: Overview of the clinical features of 7 patients). All the affected individuals presented with congenital bilateral lower limb lymphedema at birth, and lymphedema extended from the toes to the upper calves, presenting as different degrees of creases and a brawny texture of the skin (Fig. 2 - 1, 2: Bilateral lower limb lymphedema of patient II1; Fig. 2-3: Bilateral lower limb lymphedema of patient II6; and Fig. 2-4: Bilateral lower limb lymphedema of patient III3). The propositus (III3) always felt pain in her foot after taking a long walk, especially during the hot season. The swollen region was also warm to the touch, and marks caused by compression stockings were visible (Fig. 2-4: Bilateral lower limb lymphedema of patient III3). However, the phenotype of her male cousin (III4) could not be observed by the naked eye. In contrast, patient I1 complained that the edema of his legs was aggravated and extended to the roots of the thighs when he had a cold and fever in childhood. Patient II1 complained that during childhood, skin hyperkeratosis of the feet occurred, and lymphedema caused the instep to rise too high to wear shoes. The subcutaneous tissue of the foot was filled with lymphatic fluid, causing local foot and tissue swelling and deformation and adipose tissue and connective tissue proliferation (Fig. 2 - 1, 2: Bilateral lower limb lymphedema of patient II1). In adulthood, edema continued to the lower extremities beneath the knees (Fig. 2 - 1, 2: Bilateral lower limbs lymphedema of patient II1). The lymphedema is not currently visible due to plastic surgery, but the heavy edema of the lower extremities and elephant-like appearance of her legs are obvious (Fig. 2-1, 2: Bilateral lower limb lymphedema of patient II1). No other patients (II1, II2, II4, II6, III3, and III4) showed similar phenotypes under the same conditions in this family; they showed lower levels of keratinization of the foot skin and lighter swelling of the lower limbs. Hypoplastic toenails with upturned concavity were present among the patients and are consistent with "ski jump" nails (Fig. 2-3: Bilateral lower limb lymphedema of patient II6). The father of propositus (II4) showed slight epicanthic folds and downslanting palpebral fissures (Fig. 3: Slight epicanthic folds and downslanting palpebral fissures) [4]. No asymptomatic carriers or late onset or nonpenetrant cases were found in the family. No hydrocoele was found in the male members.

Table 1

Overview of clinical features of 7 patients

\begin{tabular}{|c|c|c|c|c|c|c|c|c|c|c|c|}
\hline Patient & $\begin{array}{l}\text { Onset } \\
\text { at } \\
\text { birth }\end{array}$ & $\begin{array}{l}\text { congenital } \\
\text { bilateral } \\
\text { lower limbs } \\
\text { lymphedema } \\
\text { at birth }\end{array}$ & $\begin{array}{l}\text { deep } \\
\text { creases } \\
\text { over } \\
\text { the } \\
\text { toes }\end{array}$ & $\begin{array}{l}\text { congenital } \\
\text { hands } \\
\text { edema }\end{array}$ & $\begin{array}{l}\text { brawny } \\
\text { texture } \\
\text { of the } \\
\text { skin }\end{array}$ & $\begin{array}{l}\text { small } \\
\text { dysplastic } \\
\text { toenails } \\
\text { ('ski } \\
\text { jump') }\end{array}$ & $\begin{array}{l}\text { swelling } \\
\text { of the } \\
\text { scrotum }\end{array}$ & Hypoproteinemia & Lymphedematous & $\begin{array}{l}\text { Edema } \\
\text { extends } \\
\text { to the } \\
\text { thigh }\end{array}$ & $\begin{array}{l}\text { epical } \\
\text { folds } \\
\text { down } \\
\text { slanti } \\
\text { palpe } \\
\text { fissur }\end{array}$ \\
\hline 11 & + & + & ++ & - & + & + & - & - & - & + & - \\
\hline II1 & + & + & ++ & - & + & + & - & - & - & - & - \\
\hline II2 & + & + & + & - & + & + & - & - & - & - & - \\
\hline$\| 4$ & + & $+/-$ & $+/-$ & - & $+/-$ & + & - & - & - & - & + \\
\hline 116 & + & + & + & - & + & + & - & - & - & - & - \\
\hline III3 & + & + & + & - & + & + & - & - & - & - & - \\
\hline III4 & + & $+/-$ & $+/-$ & - & $+/-$ & + & - & - & - & - & - \\
\hline
\end{tabular}

\subsection{Mutation analyses}

\subsubsection{Identification of a novel mutation in the FLT4 gene}

The Sanger sequencing results of exons 17-26 of the FLT4 gene (NM_182925.4) revealed a single nucleotide heterozygous substitution of T to A in all patients at nucleotide position 2774 (c.2774 T > A, p.V925E) in exon 20 that results in an amino acid change from valine to glutamic acid at amino acid residue 925 (Fig. 4: Sanger sequencing result of the FLT4 gene c.2774 T >A mutation.). The mutation was detected in all affected patients (I1, II1, II2, II4, II6, III3 and III4) but not in unaffected family members (II3, II5, II7 II8, III1, III2, III5 and IV1). This mutation was also ruled out as a polymorphism by HphI digestion, and the PCR fragment was $262 \mathrm{bp}$. The restriction endonuclease cleavage site is $5^{\prime} \mathrm{GGTGA}(\mathrm{N})_{8} 3^{\prime}$. If the mutation site was present, the fragment was cleaved into two fragments, which were $198 \mathrm{bp}$ and $64 \mathrm{bp}$, and analyzed by $8 \%$ polyacrylamide gel electrophoresis and silver staining. We used DL2000 as the marker (TaKaRa). The polypropylene gel electrophoresis voltage was $400 \mathrm{~V}$, and the electrophoresis time was 4 hours. Comparisons were carried out between the patients and healthy members of the family and 100 healthy controls (Fig. S1: Hphl restriction enzyme digestion results of the FLT4 gene). No mutations were found in the 100 healthy controls or the healthy members of the family. The SIFT program predicted the mutation as deleterious with a calculated score of 0.00 , which was less than the threshold of 0.05 . The PolyPhen program predicted that this mutation was likely to be damaging with a score of 1.00 . The MutationTaster website (http://www.mutationtaster.org/) also showed that V925E is a disease-causing mutation. Twelve proteins in the FLT4 subfamily were found by a BLAST search in the NCBI database (https://blast.ncbi.nlm.nih.gov/Blast.cgi) and formed a cluster in the phylogenetic tree (Fig. S2: Phylogenetic tree of the FLT4 gene). A FLT4 protein sequence alignment revealed the invariant valine in the tyrosine kinase domain, and the wild type is conserved in a wide range of organisms, ranging from humans to Danio rerio (Fig. S3: Conserved motif of the FLT4 gene). 


\section{Discussion}

Primary congenital lymphedema (PCL), also called MD (OMIM: \#153100), is caused by developmental lymphatic vascular anomalies, with an estimated prevalence of 1 in 160,000 individuals [17]. We reviewed the reported phenotypes of MD (Table S2: Review of the clinical phenotypes of Milroy disease) and found that MD patients usually exhibit lymphedema at birth with swelling of the lower limbs, and most cases are bilateral [2]. Patients often have a brawny texture and hyperkeratosis of the foot skin (Table S2: Review of the clinical phenotypes of Milroy disease). Other phenotypes associated with MD included hydrocoele in males (37\%), "ski jump" toenails (14\%) and bilateral pleural effusion [2] (Table S2: Review of the clinical phenotypes of Milroy disease). Although below-knees lymphedema is the most common phenotype of MD, edema in some patients extends to the thighs [2, 18]. Furthermore, hydrocoele is common in male patients [2, 3, 19-22].

FLT4 (NM_182925.4) gene mutations cause kinase inactivation and MD [6, 7, 22-27]. To date, all mutations have been located in two intracellular kinase domains $[6,7]$. In this study, we sequenced the tyrosine kinase coding domains of the FLT4 gene in a large family with hereditary congenital lymphedema and found a missense mutation, c.T2774A, which led to a valine-to-glutamic acid substitution (Fig. 4: Sanger sequencing result of the FLT4 gene c.2774 T-A mutation p.V925E). This missense mutation caused the major phenotypes of MD in the members of our pedigree.

Currently, researchers believe that the major pathologic changes characteristic of MD are aplastic, hypoplastic and dysfunctional cutaneous lymphatic vessels $[6,12]$, which fail to transport fluid into the venous circulation, resulting in lymphatic fluid stasis and swelling of the extremities [28-31]. That is, lymphatic vessel malformation triggers an increase in interstitial protein-rich fluid, resulting in insufficient lymphatic drainage and transport [32]. As a result, a large amount of protein-rich fluid accumulates in the tissue interstitial spaces and causes hyperplasia of the skin, subcutaneous tissue, and fibrous tissues, resulting in lymphatics that are more difficult to reflux to lymphatic vessels; edematous fluid and adipose tissue accumulate subcutaneously, followed by an inflammatory response that develops and forms a vicious cycle that aggravates the formation of edema [19, 33]. Moreover, the retarded lymphatic flow induces lipogenesis and fat deposition and leads to increased fibrocyte and connective tissue overgrowth [34-36]. Then, the affected skin thickens, hardens, and becomes rough and bulky, forming "elephant skin" over time.

The variability between MD families is high, and patients in one family can show heterogeneity. Two patients in our family suffered from specific clinical phenotypes compared with the other members: patient I1 complained that edema of both legs was aggravated and extended to the roots of the thighs when he had a cold and fever in childhood; patient II1 suffered from heavy edema of the lower extremities and an "elephant-like" skin hyperkeratosis of her legs (Fig. 2 - 1, 2: Bilateral lower limb lymphedema of patient II1) [4, 37, 38]. In contrast, neither the brawny texture of the skin nor the lymphedema of some patients was difficult to observe (II2, II4 and III4). The potential reasons for the heterogeneity in MD are not clear, and further research on FLT4 gene functions is needed to explore the causative factors. Further, genetic mutation might not be the only factor shaping the clinical manifestations of MD, and environmental, genetic, and epigenetic factors and their interactions should be considered.

\section{Conclusion}

In this report, we described a large family with manifestations of MD caused by a missense mutation in the FLT4 gene (c.2774 T >A, p.V925E).

\section{Abbreviations}

MD: Milroy disease

FLT4: Fms-related tyrosine kinase 4

VEFGR3: vascular endothelial growth factor receptor 3

PCR: polymerase chain reaction

PCL: primary congenital lymphedema

\section{Declarations}

\section{Author declarations:}

- Ethics approval and consent to participate

The research was performed with the approval of the Ethics Committee of Reproductive Health of Liaoning Province and China Medical University, and participants gave written consent to participate after being informed of the nature of the research.

\section{- Consent for publication}

Signed informed consent was obtained from all members of the studied family for publication of personal and clinical information (images included) in this research.

\section{- Availability of data and materials}

The datasets used and/or analyzed during the current study are available from the corresponding author on reasonable request. 


\section{- Competing interest}

The authors declare that there is no competing interest in this research.

\section{- Funding}

This research was funded by the Subject Construction Project of the Liaoning Key Research and Development Project, No. 2017225019; China Medical University, No. 3110118049; and the Natural Science Foundation Guidance Program of Liaoning Province, No. $2018011645-301$.

\section{- Authors' contributions}

MJ designed the project, collected the clinical data, organized the experimental results and evaluated the phenotypes for this family. YS wrote the paper, collected the clinical data, organized the experimental results, conducted the PCR experiments and sequencing analysis, interpreted the data, evaluated the phenotypes for the family with hereditary lymphedema. YPL organized the experimental results, interpreted the data. MNL organized the experimental results, interpreted the data. XN conducted the PCR experiments and sequencing analysis. XR Chen interpreted the data. HL conducted the PCR experiments and sequencing analysis.

\section{- Acknowledgments}

We thank all the individuals who participated in this study. In addition, I want to send my deepest appreciations to my parents, who cared for my young child.

\section{- Statement on compliance}

The authors all made a statement that the study is compliance with the guidelines of Key Laboratory of Reproductive Health and Medical Genetics, Liaoning Province;

The authors all made a statement that the study is compliance with the guidelines of People's republic of China.

\section{References}

1. Milroy, W.F., .An undescribed variety of hereditary oedema. N Y Med J, 1892. Nov (5).

2. Brice, G., et al., Milroy disease and the VEGFR-3 mutation phenotype. J Med Genet, 2005. 42(2): p. 98-102.

3. Gordon, K., et al., FLT4/VEGFR3 and Milroy disease: novel mutations, a review of published variants and database update. Hum Mutat, 2013. 34(1): p. 2331.

4. Connell, F., et al., A new classification system for primary lymphatic dysplasias based on phenotype. Clin Genet, 2010. 77(5): p. 438-52.

5. Esterly, J.R., CONGENITAL HEREDITARY LYMPHOEDEMA. J Med Genet, 1965. 2(2): p. 93-8.

6. Karkkainen, M.J., et al., Missense mutations interfere with VEGFR-3 signalling in primary lymphoedema. Nat Genet, 2000. 25(2): p. 153-9.

7. Irrthum, A., et al., Congenital hereditary lymphedema caused by a mutation that inactivates VEGFR3 tyrosine kinase. Am J Hum Genet, 2000. 67(2): p. 295301.

8. Kaipainen, A., et al., Expression of the fms-like tyrosine kinase 4 gene becomes restricted to lymphatic endothelium during development. Proc Natl Acad Sci U S A, 1995. 92(8): p. 3566-70.

9. Partanen, T.A., et al., VEGF-C and VEGF-D expression in neuroendocrine cells and their receptor, VEGFR-3, in fenestrated blood vessels in human tissues. FASEB J, 2000. 14(13): p. 2087-96.

10. Lohela, M., et al., Lymphangiogenic growth factors, receptors and therapies. Thromb Haemost, 2003. 90(2): p. $167-84$.

11. Coso, S., E. Bovay, and T.V. Petrova, Pressing the right buttons: signaling in lymphangiogenesis. Blood, 2014. 123(17): p. $2614-24$.

12. Mellor, R.H., et al., Lymphatic dysfunction, not aplasia, underlies Milroy disease. Microcirculation, 2010. 17(4): p. $281-96$.

13. Thompson, J.D., D.G. Higgins, and T.J. Gibson, CLUSTAL W: improving the sensitivity of progressive multiple sequence alignment through sequence weighting, position-specific gap penalties and weight matrix choice. Nucleic Acids Res, 1994. 22(22): p. 4673-80.

14. Tamura, K., et al., MEGA4: Molecular Evolutionary Genetics Analysis (MEGA) software version 4.0. Mol Biol Evol, 2007. 24(8): p. 1596-9.

15. Ng, P.C. and S. Henikoff, Predicting deleterious amino acid substitutions. Genome Res, 2001. 11(5): p. 863-74.

16. Ng, P.C. and S. Henikoff, SIFT: Predicting amino acid changes that affect protein function. Nucleic Acids Res, 2003. 31(13): p. 3812-4.

17. Smeltzer, D.M., G.B. Stickler, and A. Schirger, Primary lymphedema in children and adolescents: a follow-up study and review. Pediatrics, 1985. 76(2): p. 206-18.

18. Hurwitz, P.A. and D.J. Pinals, PLEURAL EFFUSION IN CHRONIC HEREDITARY LYMPHEDEMA (NONNE, MILROY, MEIGE'S DISEASE). REPORT OF TWO CASES. Radiology, 1964. 82: p. 246-8.

19. Gezginc, K., F. Yazici, and D. Gok, Prenatal diagnosis of Milroy's primary congenital lymphedema. Taiwan J Obstet Gynecol, 2012. 51(2): p. 280-2.

20. Dai, T., et al., A novel mutation in the conserved sequence of vascular endothelial growth factor receptor 3 leads to primary lymphoedema. J Int Med Res, 2018. 46(8): p. 3162-3171.

21. Butler, M.G., et al., A novel VEGFR3 mutation causes Milroy disease. Am J Med Genet A, 2007. 143A(11): p. 1212-7. 
22. Spiegel, R., et al., Wide clinical spectrum in a family with hereditary lymphedema type I due to a novel missense mutation in VEGFR3. J Hum Genet, 2006. 51(10): p. 846-50.

23. Ferrell, R.E., et al., Hereditary lymphedema: evidence for linkage and genetic heterogeneity. Hum Mol Genet, 1998. 7(13): p. 2073-8.

24. Evans, A.L., et al., Identification of eight novel VEGFR-3 mutations in families with primary congenital lymphoedema. J Med Genet, 2003. 40(9): p. 697703.

25. Daniel-Spiegel, E., et al., Hydrops fetalis: an unusual prenatal presentation of hereditary congenital lymphedema. Prenat Diagn, 2005. 25(11): p. 1015-8.

26. Mizuno, S., et al., Clinical variability in a Japanese hereditary lymphedema type I family with an FLT4 mutation. Congenit Anom (Kyoto), 2005. 45(2): p. 59-61.

27. Ghalamkarpour, A., et al., Hereditary lymphedema type I associated with VEGFR3 mutation: the first de novo case and atypical presentations. Clin Genet, 2006. 70(4): p. 330-5.

28. Karkkainen, M.J., et al., A model for gene therapy of human hereditary lymphedema. Proc Natl Acad Sci U S A, 2001. 98(22): p. 12677-82.

29. Jussila, L. and K. Alitalo, Vascular growth factors and lymphangiogenesis. Physiol Rev, 2002. 82(3): p. 673-700.

30. Ji, R.C., Lymphatic endothelial cells, lymphangiogenesis, and extracellular matrix. Lymphat Res Biol, 2006. 4(2): p. 83-100.

31. Zhang, S., et al., Immunohistochemical Evaluation of Histological Change in a Chinese Milroy Disease Family With Venous and Skin Abnormities. Front Genet, 2019. 10: p. 206

32. Kitsiou-Tzeli, S., et al., Milroy's primary congenital lymphedema in a male infant and review of the literature. In Vivo, 2010. 24(3): p. 309-14.

33. Tammela, T. and K. Alitalo, Lymphangiogenesis: Molecular mechanisms and future promise. Cell, 2010. 140(4): p. 460-76.

34. Smahel, J., Adipose tissue in plastic surgery. Ann Plast Surg, 1986. 16(5): p. 444-53.

35. Ryan, T.J., Lymphatics and adipose tissue. Clin Dermatol, 1995. 13(5): p. 493-8.

36. Gaffney, R.M. and J.R. Casley-Smith, Excess plasma proteins as a cause of chronic inflammation and lymphoedema: biochemical estimations. J Pathol, 1981. 133(3): p. 229-42.

37. Oduber, C.E., C.M. van der Horst, and R.C. Hennekam, Klippel-Trenaunay syndrome: diagnostic criteria and hypothesis on etiology. Ann Plast Surg, 2008. 60(2): p. 217-23.

38. Biesecker, L., The challenges of Proteus syndrome: diagnosis and management. Eur J Hum Genet, 2006. 14(11): p. 1151-7.

\section{Figures}

I

II

III

IV
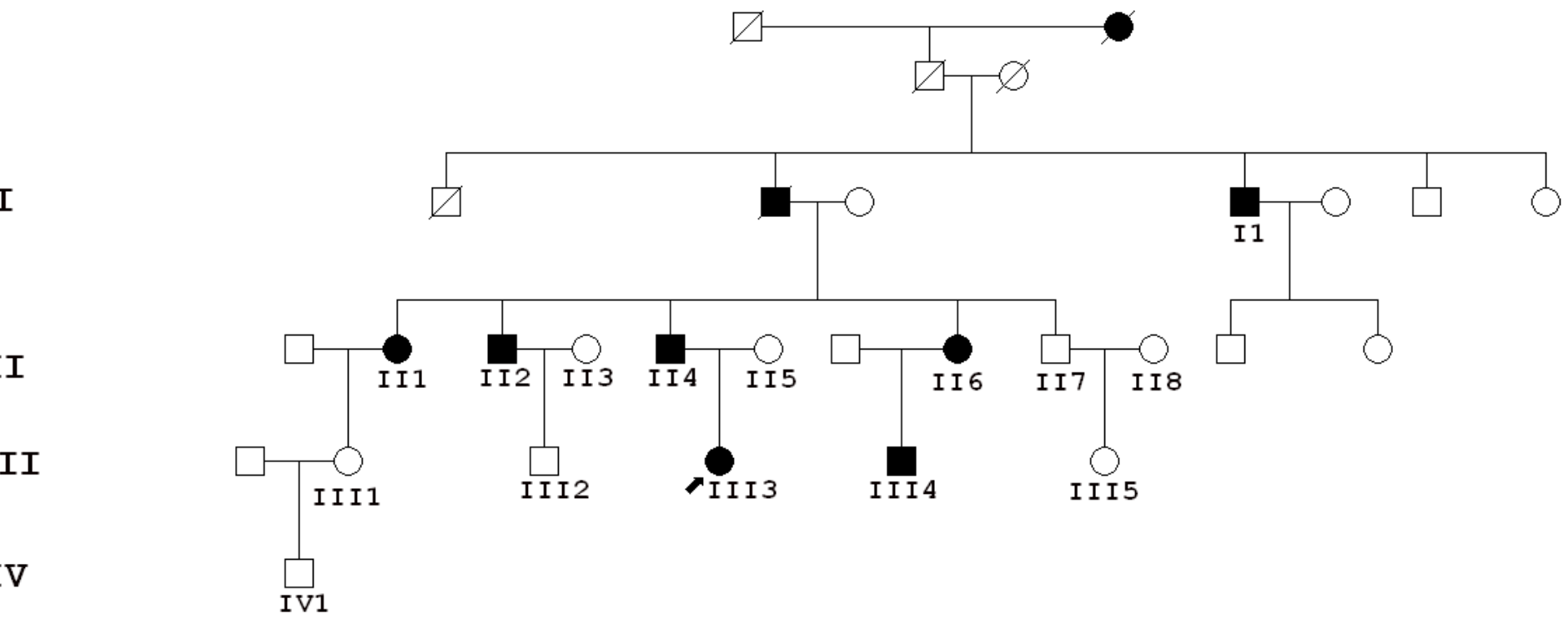

Figure 1

Pedigree of the family). Table 1 shows the clinical features of all 7 patients (Table 1: Overview of the clinical features of 7 patients 

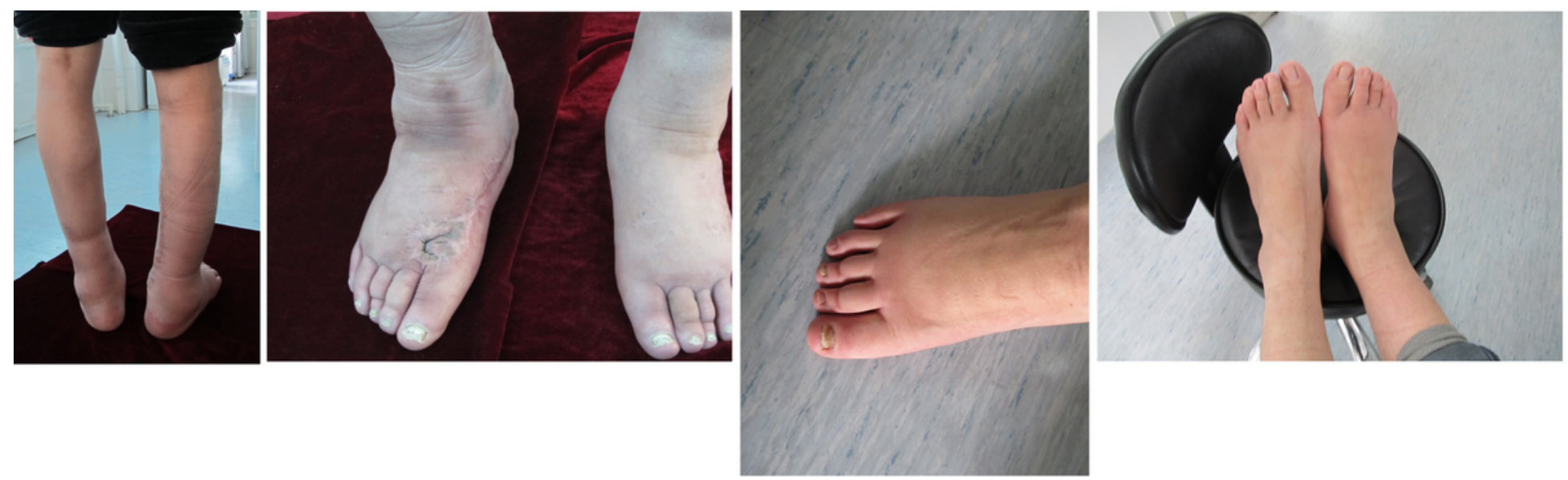

Figure 2

2-1, 2: Bilateral lower limb lymphedema of patient II1; Fig 2-3: Bilateral lower limb lymphedema of patient II6; and Fig 2-4: Bilateral lower limb lymphedema of patient III3; 2-4: Bilateral lower limb lymphedema of patient III3

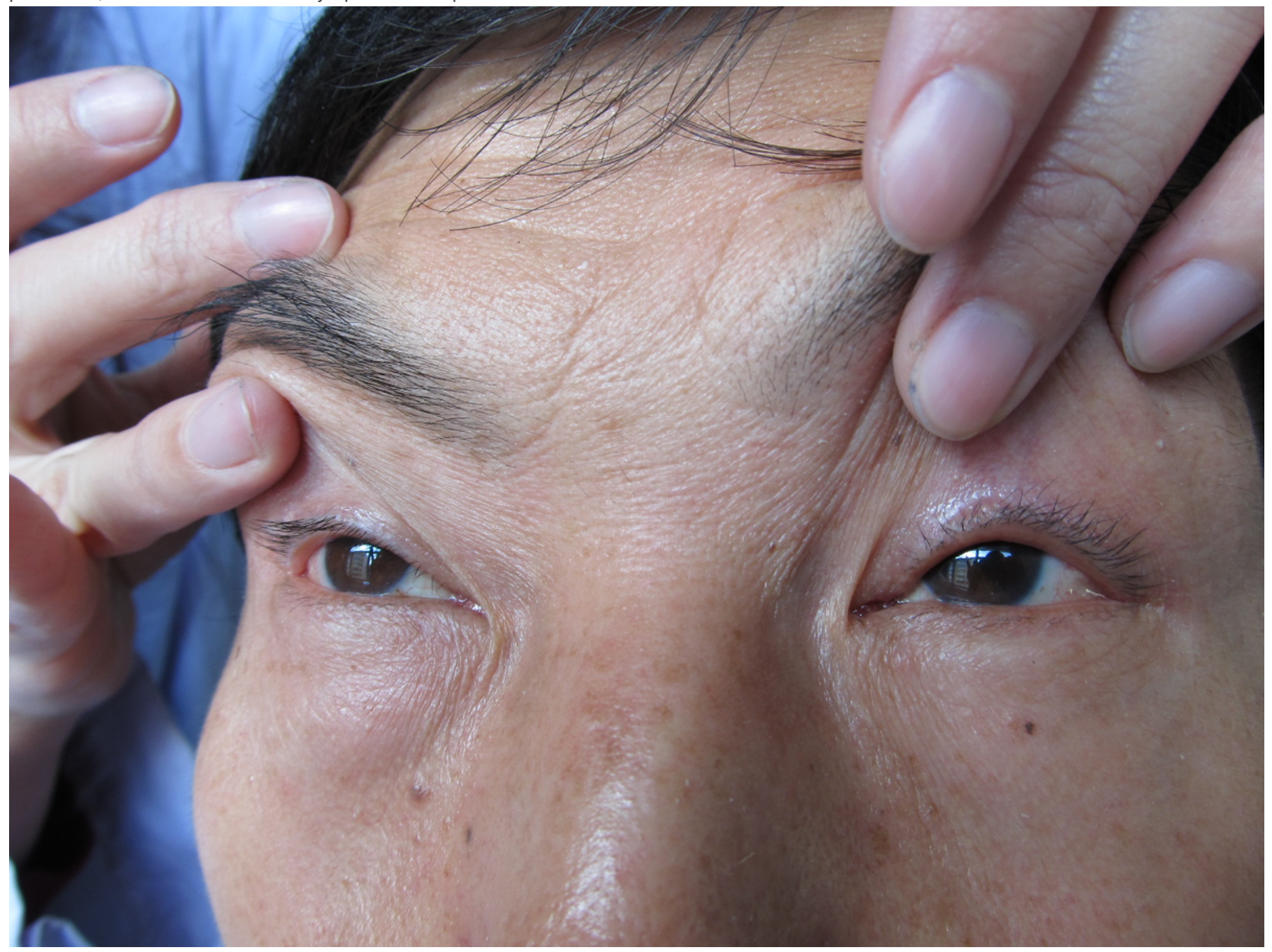

\section{Figure 3}

Slight epicanthic folds and downslanting palpebral fissures 


\section{Affected patient}

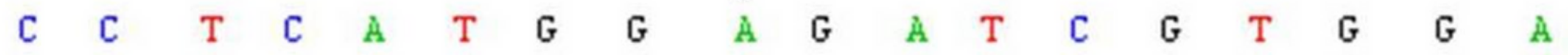

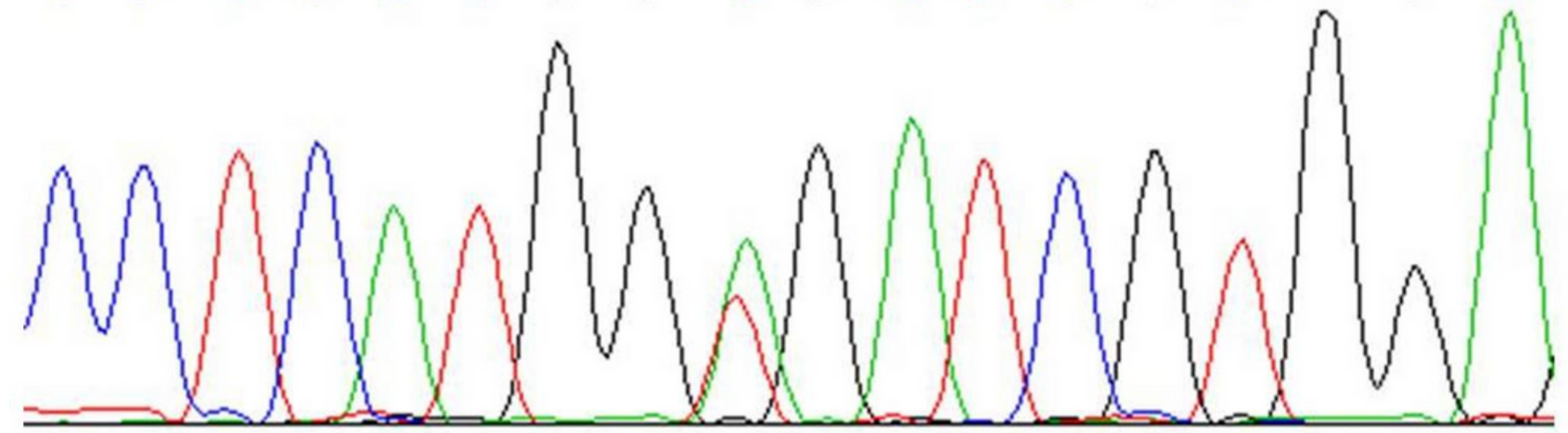

\section{Healthy control}

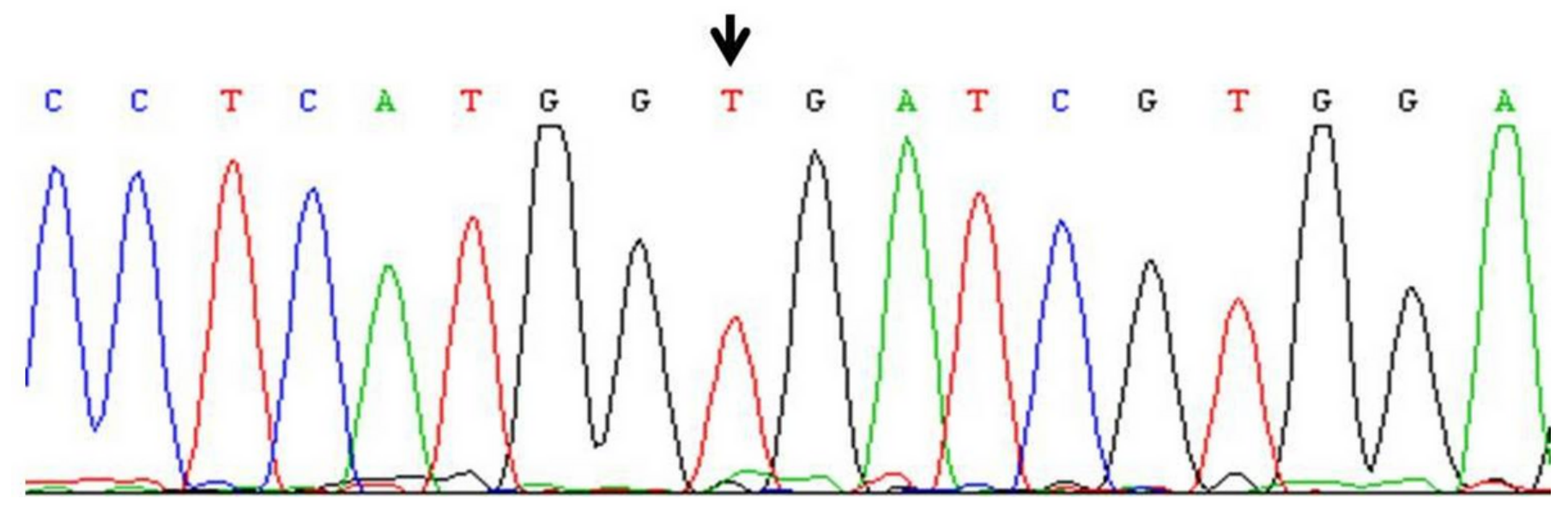

Figure 4

Sanger sequencing result of the FLT4 gene c.2774 T>A mutation.

\section{Supplementary Files}

This is a list of supplementary files associated with this preprint. Click to download.

- Fig.S1Hphlrestrictionenzymedigestionresults.tif

- Fig.S2PolygenTreeofFLT4gene.tiff

- Fig.S3ConservedmotifofFLT4gene.tiff

- TableS1.PCRamplificationofFLT4gene.docx

- TableS2.ReviewofclinicalphenotypesofMilroydisease.docx 